\title{
The Construction of Teaching Model on College English Writing from the Perspective of Cognitive Genre
}

\author{
Hao Wenjuan ${ }^{1} \&$ Liang Rui ${ }^{2}$ \\ ${ }^{1}$ School of Humanities and Social Sciences, North University of China, Shanxi, China \\ ${ }^{2}$ Wenhua Middle School, Shanxi, China \\ Correspondence: Hao Wenjuan, School of Management, School of Humanities and Social Sciences, North \\ University of China, Shanxi, China. Tel: 86-15834012292. E-mail: hwjld@163.com
}

Received: July 12, 2016 Accepted: August 20, 2016 Online Published: August 22, 2016

doi: 10.5539/elt.v9n10p31 URL: http://dx.doi.org/10.5539/elt.v9n10p31

\begin{abstract}
Teaching is a spiral rising process. A complete teaching should be composed of five parts: theoretical basis, goal orientation, operating procedures, implementation conditions and assessment. On the basis of the genre knowledge, content-based approach and process approach, this text constructs the Teaching Model of College Writing Instruction, in order to give the better guide to teaching and improve the students' ability of critical thinking and writing.
\end{abstract}

Keywords: teaching model, genre, content-based approach, process approach

\section{Introduction}

Recently, genre and genre-based pedagogy get increasingly more attention at home and aboard. Represented by Martin, the study of the genre in Sydney School was firstly applied to the discourse analysis on children's texts at primary school, the theory has been further developed and used in the classroom instructions. This is the beginning of the curriculum genre. Subsequently, the study of the genre and genre-based pedagogy of the Sydney School stepped into the second stage and the whole project focused on children's writing based on the genre knowledge and made remarkable achievements.

Most of the domestic and foreign researches about the genre and genre-based pedagogy are about the reading and reading instruction. Though the genre knowledge in teaching writing got more and more attention, the application was limited in the EAP, which was compared with ESP and EOP. However, few of them were applied into the college English writing and teaching.

\section{Teaching Model}

SiXianzhu and ZhaoHaiyan put forward a complete Teaching Model, which constitutes of five elements: 1) Goal orientation: Teaching Model is built for a specific goal. 2) Theoretical basis: it means the knowledge which can support our Teaching Model, such as philosophical, pedagogical and linguistic knowledge. 3) Realization condition: optimization of various conditions which promote the effectiveness of the Teaching Model, such as teachers, students, computers, materials, strategies and so on. 4) Procedures: specific teaching procedures. 5) Assessment, as shown in Figure 1. 


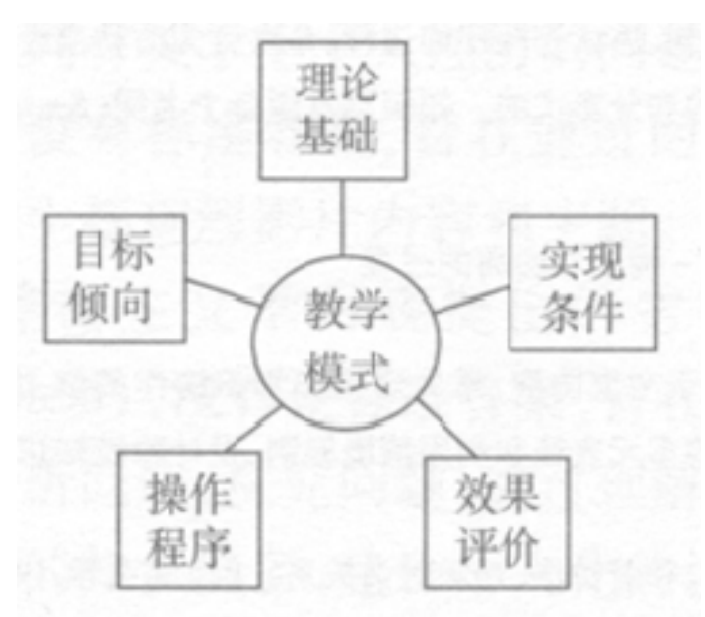

Figure 1. Relationship diagram of teaching model

The model above is consistent with the framework of teaching writing, but it doesn't show that teaching is a process. Teaching is a spiral rising process, no matter which aspect we take from. The model separates the process and ignores the whole process of teaching. So it cannot be named as Relationship Diagram. Therefore, we adjusted the diagram and considered the new diagram as a standard of our curriculum design, as shown in Figure 2.

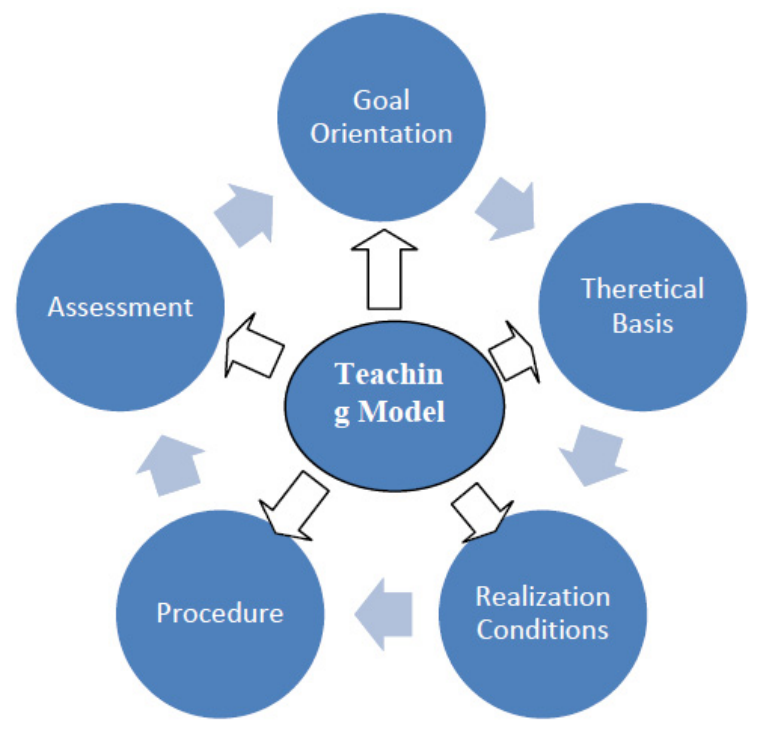

Figure 2. New relationship diagram of teaching model

From the Figure 2, we can see that a complete Teaching Model is composed of goal orientation, theoretical basis, realization conditions, procedures and assessment and it is a spiral rising process. The Teaching Model is determined by what are we doing and what achievements we want to reach, namely, goal orientation. Once the goal is settled, the theory should be chosen according to the goal and consider whether the goal based on the theory is realizable. Then corresponding methods and procedures should be applied to the implementation. Assessment, the key stage, neglected most of time, is the conclusion of the Teaching Model and the guide to the future teaching. It is the reflection of the appropriateness of Teaching Model. If we do not achieve our initial expectations, the adjustment should be done at the goal orientation stage. If results completely meet our expectations, the higher goal should be drawn up and next recheck theoretical basis, the realization conditions, procedures. 


\section{Construction of Teaching Model in College Writing Class}

\subsection{Goal Orientation}

According to the 'teaching syllabus for College English', the target of College English is to cultivate students' comprehensive ability of using English, especially the ability of listening and speaking, so that they are able to use English effectively for oral and written communication in the future work and social intercourse, and enhance their autonomous learning ability, improve their comprehensive cultural literacy, in order to meet the needs of China's economic development and international exchanges. The teaching goal of writing is that the students can complete the general writing tasks with common application style, can describe personal experiences, events, perception, emotion and so on, and they can write short passage of 120 words, which is integrated in content, appropriate in words using and coherent in discourse, according to the given topic within half an hour. The standard of writing tests and scoring are basically the same as CET.

The Teaching Model is built for the given teaching goals. Specific to the College English writing course, analyzing and categorizing the different discourses in the light of cognitive genre, trying to find an relatively independent single cognitive categories (expository, narration, argumentation and application), finding out its typical prototype and doing analysis on this prototype could improve the students' ability of critical thinking and framework competence.

\subsection{Theoretical Basis}

\subsubsection{Genre and Discourse Classification}

Genre means "kind" or "sort". In linguistics, there are different definitions about genre.

Language is realized in the form of concrete utterances (oral and written) by participants in the various areas of human activity. These utterances reflect the specific conditions and goals of each such area not only through their content (thematic) and linguistic style, that is, the selection of lexical, phraseological, and grammatical resources of the language, but above all through their compositional structure. (Bakhtin1986)

Systemic-functional linguists employ genre as part of their project to relate language use to its social context, in particular, 'the context of culture' (Martin, 2008).

$J$. R. Martin refers genre as 'to different types of texts that enact various types of social contexts... Genre is a staged, goal-oriented social processes...Social because we participate in genres with other people, Goal-oriented because we use genres to get things done and staged because it usually takes us a few steps to reach our goals' (Martin, 2003/2007).

We endorse Martin's definition here, for it focuses on function and it not only answers the question why the text might have been written or spoken, but also tells us how the goal-oriented social process is staged. It 'flags the way in which most genres take more than a single phase to unfold, the sense of frustration or incompletion that is felt when phases don't unfold as expected or planned, and the fact that genres are addresses (i.e. formulated with readers and listeners in mind), whether or not the intended audience is immediately present to respond. In these terms, as a level of context, genre represents the system of staged goal-oriented social processes through which social subjects in a given culture live their lives' (Martin, 1997).

Three schools of genre analysis should be paid attention to: ESP (the English for specific purpose), NR(The New Rhetoric) and the Sydney School. Martin is the representative of the Sydney School. Martin argues that ESP paid much attention to the content of the teaching and ignored the structure. The New Rhetoric School emphasize the discourse structure larger than the content of the text. To make up those shortcomings, the Sydney School built its own teaching method with three steps: deconstruction, joint construction, independent construction.

To improve the writing ability is to improve students' discourse competence. A discourse is a complete passage. And it is composed of two broad category of genre: social genre and cognitive genre. Social genre are similar in type to the category of text genre proposed by Pilegaard and Frandsen (1996), referring to socially recognized constructs according to which whole texts are classified in terns of their overall social purpose. Cognitive genre is used to refer to what Pilegaard and Frandsen (1996) label text type. As examples, they cite: 'narrative, expository, descriptive, argumentative or instructional text types'. For some, discourse classification is largely a social phenomenon, something directly reflected in the overall conventionally recognized purpose and conscious organization of texts: for example editorials, postcards or research texts. For others, discourse classification is a communicatively or rhetorically motivated, cognitive phenomenon, for example discourse categories such as argument, explanation, recounting, description (Ian, 2010), see Figure 3. 


\begin{tabular}{|l|l|l|}
\hline Discourse classification & social genre & Editorials, postcards, research texts \\
\cline { 2 - 3 } & cognitive genre & Argumentation, explanation, narration, description \\
\hline
\end{tabular}

Figure 3. Discourse classification

\subsubsection{Cognitive Basis}

Based on Wittgenstein's family resemblances, Rosch proposed prototype theory. Prototype is the typical member in a category, and with the largest family resemblance it has the most common features of the category members. Prototype is the schematic representation of category members, so prototype could be the cognitive reference. It involves the representation of cognitive categories in terms of the linguistics possibilities of a language (which will, employ the organizational and categorizing systems of that language), usually to achieve a social purpose in socially prescribed ways (Hyland, 2003).

Studies of isolated, single (cognitive) genres or meta-genres (Grabe, 2002; Grabe \& Kaplan, 1996) in education contexts have shown that students process and produce cognitive genres in different ways.

It is suggested that discourse creation is a process of representation. It involves representation of cognitive categories in terms of the linguistics possibilities of a language (which will, of necessity, employ the organizational and categorizing systems of that language), usually to achieve a social purpose in socially prescribed ways (Hyland, 2003).

Language users employ transactional competence in successfully interacting in everyday situations in the real world. However, the production of extended written discourse for an audience involves a real, hypothetical or imagined third party... discourse production involves the representation of a language user's understanding of concrete features of the real world, or of abstractions. That representation may involve either speech or writing (Ian, 2010).

There is no writing task is simple output, and it is the explanation for why many researchers put reading and writing together to study. Only sufficient input will produce the output. We provide students with large amount of standard language models, namely prototypes, and deconstruct them in detail. It is helpful for students to understand the characteristics and structure of a particular genre and enhance their writing ability.

\section{2.3 Sociolinguistic Basis}

Sydney School believes that genre is part of language and social contexts. 'genre theory is thus a theory of the borders of our social world, and our familiarity with what to expect... as far as its place in a functional model of language and social context is concerned, genre can be defined as a recurrent configuration of meanings and cultures as a system of genres. In our educational linguistics work with teachers we used a more accessible characterization, namely that of genre as a staged goal-oriented social process." (Martin, 1999). Sydney school's theory on the analysis of the genre has promoted the application of Systemic Functional Linguistics (SFL) to higher education all over the world. From the point of pedagogy, SFL is regarded as 'the most comprehensive and most powerful method' (Johns, 1995). From the perspective of teaching, SFL considered meaning and form as an inseparable whole. Ideational, interpersonal and textual descriptions are good for the meaning construction.

Communication is the purpose of writing. Many teachers and students have misperceived writing as a simple process of output without any communicating. In fact, the purpose of writing is to express authors' views, for the readers are more likely to understand and agree with their standpoints. In argumentation, the communicative purpose of writing is to persuade the others to accept the author's standpoints. More and more researchers have realized the significance of the reader's awareness in writing. Martin regards the genre as a process, it has three characteristics: staged, goal-oriented and social. Staged, because it usually takes us more than one phase of meaning to work through a genre; goal-oriented, because unfolding phases are designed to accomplish something and we feel a sense of frustration or incompleteness if we're stopped; social, because we undertake genres interactively with others (Martin, 2012).

\subsection{Realization Condition}

Realization condition is the combination of various conditions, including teachers, learners, materials, strategies, approaches, time, etc., which promote the Teaching Model to work effectively. It not only includes the teacher's understanding of the materials, curriculum standards, students' current level and criterion of the examinations, but also includes the teacher's control of the entire teaching process.

Teacher plays a key role in the whole process of curriculum design. The understanding of the students, the 
knowledge of the subject, the requirements of the students and the familiarity with the multimedia and other hardware devices are the advantages of first-line teachers. Therefore, the front-line teachers participated in the whole course of the Teaching Model design, including pretest for students' current writing ability and students' needs investigation. At the same time, the university also gives the positive support to the project.

\subsection{Procedure}

Most of the genre-based studies adopt the content-based approach, which is widely used in teaching reading and writing. However, content-based approach put more emphasis on the content selection and analysis, ignoring the process. For writing instruction, more scholars tend to choose process approach, which emphasizes the process but the content. Nowadays, more and more scholars begin to realize that writing is a thinking process and writing ability is the reflection of critical thinking. Therefore, a combination of two methods is adopted in our writing class design. It constitutes seven stages as process approach: planning, drafting, responding, revising, editing, evaluating and post-writing, see Figure 4.

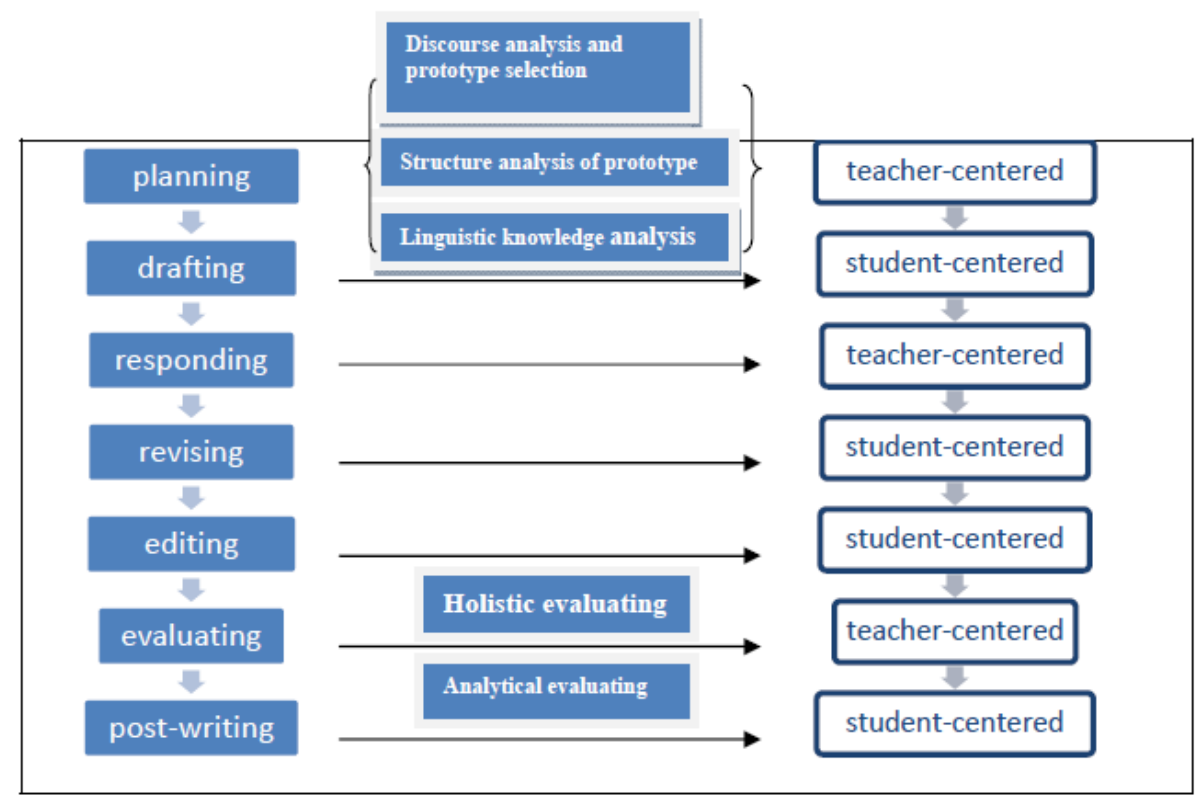

Figure 4. The combination method

\subsubsection{Planning}

The purpose of this stage is to encourage students to write, help students collect information and analyze the information critically so as to generate their own standpoints. At this stage, and teachers need to provide students with a lot of input, namely a lot of discourses, help students analyze the discourses to find the prototype of one particular genre. Then deconstruct the discourse from the point of the structural features of the genre, paragraph organization, language arrangement, the choice of the connection words and so on. This stage not only includes the genre analysis, but also includes the analysis of linguistic knowledge. The relationship between teachers and students should be interactive through the whole stage. And some approaches could be adopted, such as brainstorming group, the wh-questions and so on.

\subsubsection{Drafting}

After collecting enough information at the planning stage, the teaching process enters into the second stage, drafting. Students are required to pay more attention to the coherence and structure of the text, rather than the accuracy of grammar and vocabulary. With the help of teachers, the students should be aware of the importance of the expected readers. Although, in College English writing, most of the texts are to be handed in and the intended readers are always teachers, it is very important to help learners to realize the expected readers to improve their writing ability. To a certain extent, writing is a kind of communication, which the object is to communicate with the intended audience. The intended readers can be students' classmates, peers, family members, or pen pals, etc. According to the requirements of writing, some questions should be put forward as how to hold the reader's attention and attract readers to read on, how to raise questions and quote appropriately, 
how to end, etc.

\subsubsection{Responding}

The responding stage is particularly important in the successful implementation of process writing. Many teachers believe that the responding should be at the final stage, they mistakenly consider the responding stage as the evaluation stage, which results in the failure of teaching writing. The responding stage is the intermediate stage between drafting and revising. At this stage, the teacher should be required to make a feedback in written or oral form as soon as possible. And the responding here should be in a timely manner, and the recommendations should be based on specific points in the draft. This timely feedback can stimulate students to think critically and make appropriate adjustments.

\subsubsection{Revising}

When students revise, they review their texts on the basis of the feedback given at responding stage. They can re-analyze the prototype and their drafts, reconsider how effectively they have communicated their meanings to the reader, and how to do to make the deconstruction much clearer. At this stage, both the organization and global content of the text will be more comprehensive and clearer.

At this stage, the teacher could collect the drafts in order to avoid the recopying and ask them for rewrites. Beck (1986) suggests, 'when the students are forced to act without their original drafts, they become more familiar with their purposes and their unique messages... the writers move more ably within their topics, and their writing develops tones of confidence and authority'.

\subsubsection{Editing}

A good writer must be a good editor. Before handing in, editing is necessary. And at this stage, students are engaged in tidying up their texts as they prepared the final draft for evaluation by the teacher. It means check the correctness of grammar, words, punctuations, sentence structures, mistaken quotations, etc. It can be implemented by self-editing or mutual checking. But teachers need to give students a checklist to help students complete the process better. See Figure 5.

\section{$\diamond \quad$ Whether the spelling is correct \\ $\diamond \quad$ Whether the tense is correct \\ $\diamond \quad$ Whether the verb tense is correct \\ $\diamond$ Whether the use of prepositions and conjunctions is appropriate. \\ $\diamond \quad$ Whether the vocabulary choose is appropriate for this genre \\ $\diamond \quad$ adjectives and adverbs is appropriate or not \\ $\diamond \quad$ whether the clause is correct \\ $\diamond \quad$ whether the sentence is complete}

Figure 5. The checklist to help students complete the process better

\subsubsection{Evaluating}

The evaluating stage is teacher-based. Evaluation should be divided into the holistic evaluation and analytical evaluation. The holistic evaluation is a macro evaluation, such as: the overall interpretation, the reader's awareness, the relevance of the viewpoint, ideas and structures, etc. analytical evaluation is evaluation in details of the writing ability. Analytical evaluation helps learners to recognize their own deficiencies, and pay more attention to these problems and correct them consciously in the future writing.

\subsubsection{Post-writing}

Post-writing provides learners with a new understanding of their texts, and it makes them be more clearly aware of their shortcomings in writing, which becomes the motivation of learners to further writing. At this Stage, the students will contrast with prototypes again, recheck their texts and rewrite as soon as they got the feedback from teachers. It is the process of self-improvement. The process of rewriting can guarantee the circulation of the whole teaching process, improve the students' ability to think critically, thus ensure the continuous improvement of students' writing ability. 


\subsection{Curriculum Evaluation}

Teaching is a spiral rising process. A reasonable course assessment will play a positive role in promoting the curriculum, on the contrary, inaccurate assessment is one of the main reasons for the failure of the course. Curriculum evaluation should include two aspects: summative assessment and formative assessment. The summative assessment emphasizes the final outcome of the teaching, but formative assessment is more focused on the development and change process of teaching. An effective evaluation system should include both the process and the results. Formative assessment in the teaching process can be realized by different approaches, such as quits, observations, interviews, etc. It is helpful for teachers to find problems in time and make adjustment to the teaching materials, methods, strategies and so on, and making the teaching process to carry out smoothly. Summative evaluation is the final evaluation of the course. It is helpful for teachers and related organizations to understand the completion of the objectives of the course and make the right decisions.

\section{Conclusion}

The teaching of college English writing is not only a cyclical process, but also a rising process. In each cycle, there should be improvement in students' ability of critical thinking, discourse competence, linguistic capability and communicative competence. With SiXianzhu and ZhaoHaiyan's Teaching Model as a template and the genre knowledge as theory basis, the paper puts forward its own Teaching Model for English writing class. It is hoped that the model can play a guiding role in the class of college English writing and the curriculum design of writing class. In future, based on the further classification of the genre from the social and cognitive perspective, this Teaching Model could be applied into the curriculum design of ESP and EAP. It has become the future direction of the study, and laid a foundation for the ESP and EAP Writing Curriculum design.

\section{Acknowledgements}

Foundation item: The Projects of Philosophy and Social Sciences of North University of China.

\section{References}

司显柱, 赵海燕. (2013). 建构主义教学模式视阈中的大学英语课程设计. 外语电化教学 (In Chinese).

Bakhtin, M. M. (1986). The problem of speech genres. In M. M. Bakhtin (Ed.), Speech Genres and Other Late Essays (pp. 60-102). Translated by V. MCGee. Austin: University of Texas Press.

Beck, T. (1986). Two activities that encourage real revision. Practical ideas for teaching writing as a process. Sacramento: California State Department of Education.

Fillmore, C. J. (1985). Linguistics as a tool for discourse analysis. In T. A. Van Dijk (Ed.), Handbook of Discourse Analysi (Vol. 1, pp. 11-39). London: Academic Press.

Grabe, W. (2002). Narratie and expository macro-genres. In A. Johns (Ed.), Genre in the Classroom: Multiple Perspectives (pp. 249-67). Mahwah, NJ: Erlbaum.

Grabe, W., \& Kaplan, R. B. (1996). Theory and Practice of Writing: An Applied Linguistic Perspective. New York: Longman.

Hyland, K. (2003). Discourse analysis in second language research. Journal of Second Language Writing, 12, 166. http://dx.doi.org/10.1017/CBO9780511667251

Ian, B. (2010). Academic writing and genre: a systematic analysis. London: Continuum International Publishing Group.

Jack, C. R., \& Willy, A. R. (2002). Methodology in Language Teaching: An Anthology of Current Practice. London: Cambridge University Press.

Johns, A. M. (1995). Genre and pedagogical purpose. Journal of Second Language Writing, 4(2), 181-190. http://dx.doi.org/10.1016/1060-3743(95)90006-3

Martin, J. R. (1997). Analysing genre: functional parameters. In F. Christie, \& J. Martin (Eds.), Genre and Institutions: Social Processes in the Workplace and School (pp. 3-39). London: Cassell.

Martin, J. R. (2003). Grammar for explanation. In J. R. Martin, \& R. Wodak (Eds.), Re/Reading the Past: Critical and Functional Perspectives on Discourse of History (pp. 19-57). Amsterdam: Benjamins. http://dx.doi.org/10.1075/dapsac.8.03mar

Martin, J. R. (2007). Construing knowledge: a functional linguistic perspective. In F. Christie, \& J. R. Martin (Eds.), Language, Knowledge and Pedagogy: Functional linguistic and Socialogical Perspectives (pp. 34-66). London: Casswll. http://dx.doi.org/10.1215/0961754X-2007-027 
Martin, J. R. (2012). Language in Education. Shanghai: Shanghai Jiao Tong University Press. http://dx.doi.org/10.1021/la3022134

Martin, J. R., \& Rose, D. (2008). Genre Relations: Mapping Culture. London: Equinox.

Pilegaard, M., \& Frandsen, F. (1996). 'Text type'. In J. Verschueren, J.-O. Oastaman, J. Blommaert, \& C. C. Bulcaen (Eds.), Handbook of Pragmatics 1996 (pp. 1-13). Amsterdam: John Benjamins.

\section{Copyrights}

Copyright for this article is retained by the author(s), with first publication rights granted to the journal.

This is an open-access article distributed under the terms and conditions of the Creative Commons Attribution license (http://creativecommons.org/licenses/by/4.0/). 